\section{Intrapleural placement of a nasogastric tube: an unusual complica- tion of nasotracheal intubation}

David N. Fisman MD, Michael E. Ward MD PhD FRCPC
Purpose: Although rare, the misplacement of nasogastric tubes into the pleural space has been described. The prognosis of such injuries is improved by prompt recognition; therefore, it is important for physicians who practice nasogastric intubation to be aware of this potential complication, and to be familiar with an approach to early diagnosis.

Clinical features: We present a case of perforation of the cervical oesophagus by a polyvinylchloride nasogastric tube, following a traumatic attempt at nasotracheal intubation. This resulted in passage of the nasogastric tube into the pleural space.

Conclusions: Our experience with this case and a review of the relevant literature suggest that such trauma may predispose to malplacement of nasogastric tubes. Clinical signs, such as aspiration of fluid from a nasogastric tube, and auscultation of air insufflated into the stomach, are unreliable; however, the presence of subcutaneous air in the neck on chest radiograph, and the presence of cervical crepitance on physical examination, are valuable signs in the early diagnosis of perforation of the cervical oesophagus. Contrast oesophagog. raphy remains the diagnostic manoeuvre of choice in confirming the diagnosis, but early diagnosis will depend on a high index of suspicion and prompt viewing of chest $x$-rays. The management and the prognosis of such injuries depends on the level of the perforation, delays in diagnosis, and the presence of associated mediastinitis.

\section{Key words}

COMPLICATIONS: oesopheageal perforation; INTUBATION: complications.

From the Divisions of Critical Care and Pulmonary Medicine, Royal Victoria Hospital, McGill University, Montréal, Québec, Canada.

Address correspondence to: Dr. Michael E. Ward, Rm. L3.05, Royal Victoria Hospital, 687 Pine Ave West, Montréal, Québec, H3A 1 A 1.

Phone: 514-842-1231 ext. 4643. Fax: 514-843-1687.

email: mward@rvhmed.lan.mcgill.ca

Accepted for publication July 21, 1996.
Objectif: Malgré sa rareté, l'introduction accidentelle d'une sonde nasogastrique dans l'espace pleural a déjà été décrite. Le diagnostic précoce peut permettre d'améliorer le pronostic de cette complication. Il est donc important que les médecins qui pratiquent le tubage nasogastrique connaissent cette complication éventuelle et soient capables de la diagnostiquer très tôt.

Eléments cliniques: Les auteurs présentent le cas d'une perforation oesophagienne cervicale. Cette complication causée par une sonde nasogastrique en chlorure de polyvinyle est survenue à la suite d'une tentative d'intubation nasotrachéale traumatique. La sonde a alors pénétré dans l'espace pleural. Conclusion: Notre expérience actuelle et une revue de la littérature pertinente suggèrent que ce type de traumatisme peut prédisposer à l'installation fautive de sondes nasogastriques. Les signes cliniques comme l'aspiration de liquide par la sonde et l'auscultation d'air insuffé dans l'estomac ne sont pas fiables; cependant, l'image radiologique d'air souscutané cervical et la présence de crépitations à l'examen physique du cou sont des signes valides de la perforation oesophagienne cervicale. L'oesophagographie de contraste permet de confirmer le diagnostic mais un haut degré de soupçon et un examen rapide de la radiographie du thorax permettent un diagnostic précoce. La prise en charge et le pronostic de ces lésions sont tributaires du niveau de la perforation, de la précocité du diagnostic et présence d'une médiastinite.

Misplacement of nasogastric tubes into the pleural space is a rare occurrence, generally associated with transbronchial placement of narrow-bore feeding tubes with metal stylets. ${ }^{1,2}$ We present a case which illustrates the potential for intrapleural placement of a polyvinyl chloride nasogastric tube following traumatic nasotracheal intubation. The case highlights the possibility of oesophageal perforation during both nasogastric and nasotracheal intubation, and the potential for particularly severe injury when complications of both procedures occur in tandem. Since nasogastric intubation often fol- 
lows nasotracheal intubution, the setting in which this complication arose is common among critically ill patients and patients undergoing general anaesthesia. For this reason, and because the prognosis of oesophageal perforation depends greatly on prompt recognition and treatment, ${ }^{3.4}$ it is important that physicians caring for such patients be apprised of this complication and the factors which increase the risk of its occurrence.

\section{Case report}

A 76-yr-old woman was admitted to hospital with a fracture of her left tibia and fibula resulting from a fall. Past medical history was remarkable for chronic renal failure, requiring peritoneal dialysis, and carcinoma of the right breast treated surgically five years before admission. In hospital, the patient developed abdominal pain. Examination of peritoneal fluid revealed no leukocytes or bacteria. The serum amylase was noted to be elevated to $1350 \mathrm{U} \cdot \mathrm{L}^{-1}$ (normal range $20-130 \mathrm{U} \cdot \mathrm{L}^{-1}$ ).

Over the next $48 \mathrm{hr}$ she became increasingly obtunded, hypothermic, and hypotensive, and was transferred to the intensive care unit (ICU). Arterial blood gases on supplemental oxygen demonstrated hypoxaemia and a metabolic acidosis. Serum amylase at the time of ICU admission was $133 \mathrm{U} \cdot \mathrm{L}^{-1}$.

Mechanical ventilation was instituted through an 8 $\mathrm{mm}$ internal diameter (ID) orotracheal tube, and blood pressure was supported with norepinephrine. A CT scan of the abdomen revealed oedematous loops of bowel and a normal pancreas. In response to antibiotic therapy and supportive measures the patient improved and the trachea was extubated on the third day after ICU admission.

Three days later, she once again developed abdominal pain, hypotension, and respiratory distress; the serum amylase was $81 \mathrm{U} \cdot \mathrm{L}^{-1}$. A diagnosis of ischaemic colitis was made and she was taken to the operating room. As she was haemodynamically unstable and developed severe dyspnoea in the recumbent position, conscious blind nasotracheal intubation was attempted using a 7 $\mathrm{mm}$ ID tracheal tube, but was unsuccessful. Trauma to the pharynx was suspected on the basis of a small amount of blood in the pharynx and nasotracheal tube. Orotracheal intubation with an $8 \mathrm{~mm}$ ID endotracheal tube was performed, and a \#16 French polyvinylchloride nasogastric tube was inserted through the right nostril. The nasogastric tube was passed to $60 \mathrm{~cm}$ without resistance, and was noted to drain $50 \mathrm{ml}$ clear fluid. Laparotomy revealed normal bowel, and an oedematous pancreas, with diffuse calcification. A diagnosis of pancreatitis was made, the abdomen was closed, and the patient was returned to the ICU.

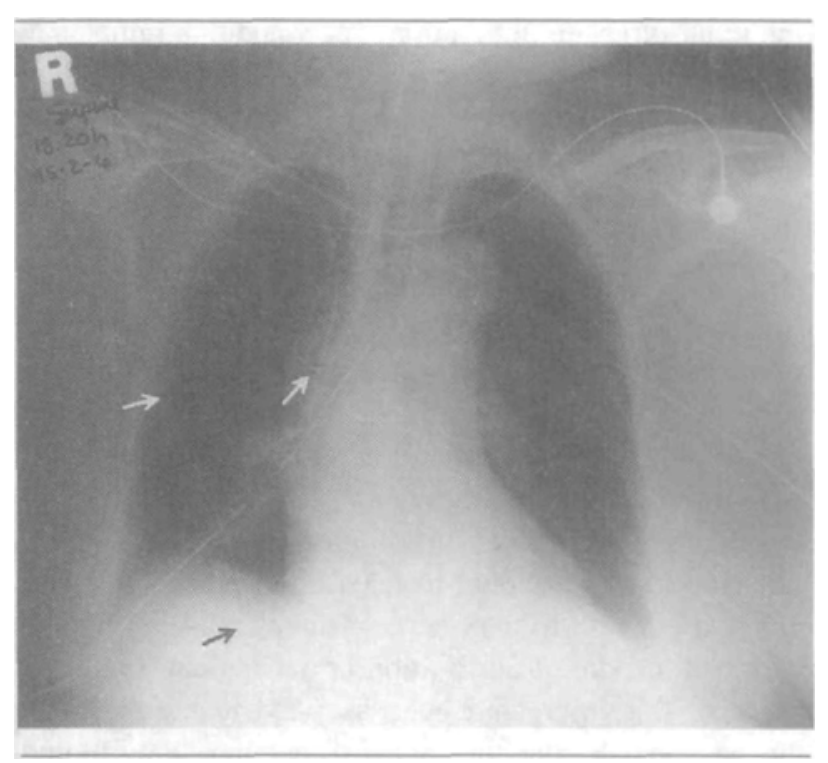

FlGURE Postoperative chest radiograph, with nasogastric tube passing through the cervical oesophagus, tracking along the mediastinum, and entering the right pleural space at the level of the hilum. Subcutaneous emphysema is noted in the neck. Surgical clips in the right axilla are the result of the previous segmental mastectomy and axillary node dissection.

The postoperative chest radiograph (Figure) showed the nasogastric tube leaving the oesophagus in the neck, track along the mediastinum to the level of the right hilum, and exit into the right pleural space. Subcutaneous emphysema is noted in the neck. Upper gastrointestinal endoscopy demonstrated perforation of the oesophagus by the nasogastric tube $15 \mathrm{~cm}$ from the incisors.

A chest tube was placed to drain the pleural space, and the patient was returned to the operating room. Neck dissection located the tube where it passed through a $2 \mathrm{~cm}$ tear in the cricopharyngeus muscle. The nasogastric tube was retrieved and redirected into the oesophagus. The cricopharyngeus tear was repaired, and a drain was left in place.

Postoperative management consisted of respiratory and haemodynamic supportive measures, broad spectrum antibiotic therapy, and total parenteral nutrition. On the fourth postoperative day she once again developed abdominal pain, hypotension and respiratory distress, and died shortly thereafter of progressive shock and respiratory failure. Permission for autopsy was denied.

\section{Discussion}

Two important points are illustrated by this case: (1) Transoesophageal intubation of the pleural space with a nasogastric tube may occur as a complication of trau- 
matic nasotracheal intubation; (2) Since this injury may occur in a setting where clinical signs are unreliable, a high index of suspicion and prompt viewing of chest radiographs are required to effect prompt diagnosis and treatment.

Primary perforation of the cervical oesophagus or pharynx by a nasogastric tube is a rare complication and was not noted to occur at all in a recent review of 340 nasogastric intubations. ${ }^{7}$ Oesophageal perforation resulting in intubation of the mediastinum and pleural space is even more uncommon and, to our knowledge, only three cases have been documented. ${ }^{5,6}$ In two previously reported patients with high oesophageal perforation, the tube was noted to leave the cervical oesophagus at the level of the cricopharyngeus muscle. ${ }^{11,12}$ This was also the site of perforation in our patient. Predisposition to this injury has been ascribed to narrowing of the oesophagus and the lack of an outer, longitudinal layer of muscle fibres at this level. ${ }^{13} \mathrm{~A}$ number of factors which may predispose to oesophageal perforation by nasogastric tubes have been proposed. ${ }^{2,8}$ These include repeated attempts to pass the tube, preexisting anatomical abnormalities of the oesophagus, altered mental status, cardiomegaly, tracheal intubation, and the presence of cervical osteophytes. With the exception of tracheal intubation, which has been the subject of a small retrospective study, ${ }^{2}$ the association of these factors with oesophageal perforation is based on anecdotal data and may be attributable to their higher prevalence among patients requiring nasogastric intubation. Of these putative risks factors, only tracheal intubation and altered mental status are identifiable in the current patient.

In this case, an attempt at nasotracheal intubation was followed by easy passage of a nasogastric tube. This sequence suggests that the initial oesophageal laceration occurred during the intubation with subsequent passage of the nasogastric tube through the laceration. One previous case of difficult orotracheal intubation associated with subsequent oesophageal perforation by a nasogastric tube has been reported ${ }^{12}$ and a similar mechanism of injury was proposed. The risk of oesophageal or pharyngeal perforation during tracheal intubation is increased in the presence of abnormal neck anatomy. ${ }^{14}$ Oesophageal perforation is reported to occur more commonly in the context of emergency intubation by an inexperienced individual ${ }^{15}$ but has also been documented following elective orotracheal intubation by experienced anesthetists. ${ }^{16}$

Nasotracheal intubation has been considered to carry a greater theoretical risk of pharyngeal or high oesophageal perforation, due to the blind nature of the procedure. ${ }^{17}$ In practice, however, this complication is uncommon. Neither oesophageal nor pharyngeal perforation was reported as a complication in two recent, large patient series after nasotracheal intubation. ${ }^{18,19}$ In a recent series of 52 cases of oesophageal perforation, however, three perforations secondary to emergency blind nasotracheal intubation were reported. ${ }^{10}$

Since the prognosis of oesophageal perforation depends greatly on rapid diagnosis and treatment, ${ }^{3,4}$ it is important to review the sensitivity of traditional clinical manoeuvres in the detection of nasogastric tube misplacement and oesophageal rupture. Since this complication occurs in the setting of anaesthetized or sedated patients, clinical evidence that a problem has occurred may be minimal.

Subcutaneous emphysema was noted radiographically in our patient but cervical crepitance was absent. In two of three previous cases of transoesophageal intubation of the pleural space by nasogastric tubes, ${ }^{6,7}$ prominent subcutaneous emphysema was apparent radiographically in the neck, and cervical crepitance was noted in one case. In a series reported by Han et al. ${ }^{20}$ subcutaneous emphysema in the neck was present in 12 of 24 patients with oesophageal perforation resulting from various causes. Four of the 24 patients had perforation of the cervical oesophagus and all of these were noted to have subcutaneous emphysema in the neck. ${ }^{20}$ Cervical crepitance has been reported to occur in $60 \%$ of perforations of the cervical oesophagus, and one third of midoesophageal perforations, but is uncommon following distal oesophageal perforation. ${ }^{9}$ Other radiographic findings in oesophageal perforation at all levels include pneumothorax, pneumomediastinum, and pleural effusions. Twelve percent of individuals with oesophageal perforation will have no radiographic evidence of perforation. ${ }^{20}$

The diagnosis was further obscured in our patient, because fluid (presumably from the pleural space) was aspirated from the nasogastric tube, and was felt to represent gastric contents. Several previous reports of nasogastric tube misplacement have noted that both aspiration of "gastric contents" and auscultation of air insufflated into the stomach are unreliable methods of confirming correct tube placement. The sound of bubbling air is transmitted as easily from the lung or pleural space as it is from the stomach. ${ }^{5-8}$ Others, ${ }^{21}$ have recommended the measurement of the $\mathrm{pH}$ of aspirated fluid to confirm gastric placement. However, the widespread use of $\mathrm{H}_{2}$-antagonists in critically ill patients is likely to diminish the specificity of a high fluid $\mathrm{pH}$ in this setting.

Once oesophageal perforation is suspected, confirmation of the diagnosis has traditionally been by contrast oesophagography. While water soluble contrast is safer in the case of large perforations, it is less sensitive than 
barium with small perforations, and may result in pulmonary oedema if aspirated in significant quantities. ${ }^{22}$ As a result, some authors recommend an initial examination with water soluble contrast, followed by oesophagography with a small amount of barium if negative, or, if there is considerable risk of aspiration or tracheooesophageal communication, the use of thinned barium preparations. ${ }^{3}$ Although oesophagography remains the standard for detection of oesophageal perforation, computerized tomography (CT) will provide a valuable adjunct when mediastinitis or fistula formation are suspected. ${ }^{23}$

Optimal surgical management of oesophageal perforation is discussed in detail elsewhere, ${ }^{3,4}$ however, both the approach to management and prognosis of such injuries will depend on the level of the perforation (cervical or thoracic), the time elapsed between perforation and diagnosis and the presence or absence of mediastinitis.

Perforation of the cervical oesophagus may not require primary closure, while perforation of the thoracic oesophagus is generally associated with mediastinitis, and so usually requires thoracotomy. The overall mortality rate of oesophageal perforation from all causes is approximately $21 \%$, compared with $6 \%$ in uncomplicated cervical oesophageal perforation. . $^{3,4}$

In this case, a tract extending from the retropharyngeal space to the mediastinum was established by the nasogastric tube. This likely resulted in mediastinal contamination, and so primary repair of the oesophageal laceration was undertaken.

When diagnosis is delayed for more than $24 \mathrm{hr}$, successful primary closure becomes unlikely, because of local inflammation and breakdown of the oesophagus, and oesophageal exclusion or diversion procedures become more practical. Mortality has been reported to increase by 12 to $32 \%$ when diagnosis is delayed beyond $24 \mathrm{hr}^{3,4}$

In this case, severe pancreatitis may have been the cause of death, and the natural history of the injury in this patient is, therefore, obscured. The published experience with high oesophageal perforation with pleural intubation, however, suggests that, in the absence of such interceding factors, a favourable outcome may be anticipated. In the three cases cited previously, ${ }^{6,7}$ treatment consisted of intravenous antibiotics and, in two patients, closed chest tube drainage. All of these patients recovered.

In summary, both nasogastric and nasotracheal intubation may result in oesophageal perforation. Either manoeuvre may be complicated by intubation of the mediastinum or pleural space by a nasogastric tube. Traditional measures, such as air insufflation and aspira- tion of fluid, are of little use in determining correct placement of nasogastric tubes, other clinical signs, such as cervical crepitance, and elevated $\mathrm{pH}$ of aspirated fluid, may provide valuable clues in the diagnosis of nasogastric tube misplacement. Plain chest roentgenograms will show evidence of free air or subcutaneous emphysema in the majority of cases. The fact that these injuries may initially be clinically silent makes a high index of suspicion important, as prognosis depends on early diagnosis. Although cervical oesophageal perforation may be managed conservatively, the presence of mediastinitis warrants more aggressive treatment.

\section{References}

1 Katelaris $P H$. Pleuropulmonary complications of fine bore naso-enteric feeding tubes. Aust NZ J Surg 1991; 61: 39-42.

2 Carey TS, Holcombe BJ. Endotracheal intubation as a risk factor for complications of nasoenteric tube insertion. Crit Care Med 1991; 19: 427-9.

3 Jones WG II, Ginsberg RJ. Esophageal perforation: a continuing challenge. Ann Thorac Surg 1992; 53: 534-43.

4 Bladergroen MR, Lowe JE, Postlethwait RW. Diagnosis and recommended management of esophageal perforation and rupture. Ann Thorac Surg 1986; 42: 235-9.

5 Patow CA, Pruet CW, Fetter TW, Rosenberg SA. Nasogastric tube perforation of the nasopharynx. South Med J 1985; 78: 1362-9.

6 Siemers PT, Reinke RT. Perforation of the nasopharynx by nasogastric intubation: a rare cause of left pleural effusion and pneumomediastinum. Am J Roentgenol 1976; 127 : 341-3.

7 Ghahremani GG, Gould RJ. Nasoenteric feeding tubes. Radiographic detection of complications. Dig Dis Sci 1986; 31: 574-85.

8 Jackson RH, Payne DK, Bacon BR. Esophageal perforation due to nasogastric intubation. Am J Gastroenterol 1990; 85: 439-42.

9 Sarr MG, Pemberton JH, Payne WS. Management of instrumental perforations of the esophagus. J Thorac Cardiovasc Surg 1982; 84: 211-8.

10 White RK, Morris DM. Diagnosis and management of esophageal perforations. Am Surg 1992; 58: 112-9.

11 Tiller HJ, Rhea WG Jr. Iatrogenic perforation of the esophagus by a nasogastric tube. Am J Surg 1984; 47 : 423-5.

12 Norman EA, Sosis $M$. Iatrogenic oesophageal perforation due to tracheal or nasogastric intubation. Can Anaesth Soc J 1986; 33: 222-6.

13 Seybold WD, Johnson MA, Leary WV. Perforation of the esophagus. An analysis of 50 cases and an account of experimental studies. Surg Clin N Am 1950; 30: 1155-83.

14 Dubost C, Kaswin D, Duranteau A, Jehanno C, Kaswin $R$. 
Esophageal perforation during attempted endotracheal intubation. J Thor Cardiovasc Surg 1979; 78: 44-50.

15 Hawkins DB. Seltzer DC, Barnett TE. Stoneman $G B$.

Endotracheal tube perforation of the hypopharynx. West J Med 1974; 120: 282-6.

16 Johnson $K G$, Hood $D D$. Esophageal perforation associated with endotracheal intubation. Anesthesiology 1986; 64: 281-3.

17 Tintinalli JE, Claffey J. Complications of nasotracheal intubation. Ann Emerg Med 1981; 10: 142-4.

18 Black AE, Hatch DJ, Nauth-Misir N. Complications of nasotracheal intubation in neonates, infants and children: a review of 4 years' experience in a children's hospital. $\mathrm{Br} \mathrm{J}$ Anaesth 1990; 65: 461-7.

19 Holdgaard HO, Pedersen J, Schurizek BA, Melsen NC, $J u h l B$. Complications and late sequelae following nasotracheal intubation. Acta Anaesthesiol Scand 1993; 37: 475-80.

20 Han SY, McElvein RB, Aldrete JS, Tishler JM. Perforation of the oesophagus: correlation of site and cause with plain film findings. AJR Am J Roentgenol 1985; 145: 537-40.

21 James $R H$. An unusual complication of passing a narrow bore nasogastric tube. Anaesthesia 1978; 33: 716-8.

22 Foley MJ, Ghahremani GG, Rogers LF. Reappraisal of contrast media used to detect upper gastrointestinal perforations. Comparison of ionic water-soluble media with barium sulfate. Radiology 1982; 144: 231-7.

23 Backer CL, LoCicero J, Hartz RS, Donaldson JS, Shields $T$. Computed tomography in patients with esophageal perforation. Chest 1990; 98: 1078-80. 